\title{
Body mass index and employment status: a new look
}

\section{Jonas Minet Kinge}

Norwegian Institute of Public Health and

Department of Health Management and Health Economics,

University of Oslo

\section{UNIVERSITY \\ OF OSLO}

HEALTH ECONOMICS

RESEARCH NETWORK

Working paper 2015: 3

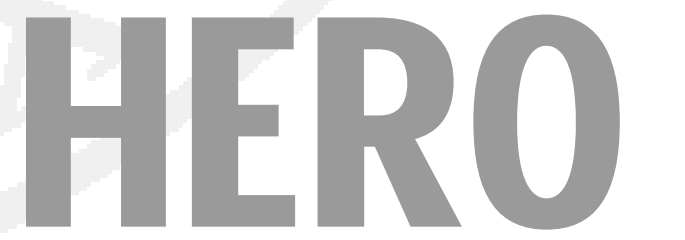




\title{
Body mass index and employment status: a new look
}

\author{
August 2015
}

\author{
Jonas Minet Kinge (Jonas.Minet.Kinge@fhi.no) \\ Department of Health Statistics, Norwegian Institute of Public Health, Norway \\ Department of Health Management and Health Economics, University of Oslo, Norway
}

\section{ABSTRACT \\ Background}

Earlier literature has usually modelled the impact of obesity on employment status as a binary choice (employed, yes/no). I provide new evidence on the impact of obesity on employment status by treating the dependent variable as a as a multinomial choice variable. Using data from a representative English survey, with measured height and weight on parents and children, I define employment status as one of four: working; looking for paid work; permanently not working due to disability; and, looking after home or family. I use a multinomial logit model controlling for a set of covariates and I instrument for BMI based on genetic variation in weight. I find that BMI and obesity has a statistically significant impact on the probability of "not working due to disability". The results for the other employment outcomes are less clear. My findings also suggest that the reason for the impact of obesity on employment is due to obesity being a deliberating health condition. Factors other than health may be less important in explaining the impact of BMI/obesity on employment. 


\section{Introduction}

Obesity has been argued to have an impact on labour market outcomes for the following reasons:

i. Obesity is a condition that reduces ability to work by being a risk factor for a wide number of deliberating diseases, including coronary heart disease, type II diabetes, hypertension and stroke (NHLBI Obesity Education Initiative, 1998).

ii. Obesity has an impact on certain characteristics that might reduce performance in the labour market, such as lower self-esteem, lower reservation wages and/or higher discount rates (Komlos et al., 2004, Offer, 2001).

iii. There may be discrimination against the obese due to their physical attributes. As discussed by Morris (2007) there may be three reasons for this. First, prejudice by employers, reflecting their distaste for obese workers and the psychological costs incurred when dealing with them (McLean and Moon, 1980). Second, there may be stereotyping by employers, arising from a belief that the obese are less productive (Everett, 1990). Third, discrimination may arise through uncertainty, or a lack of knowledge about the productivity of obese workers (Pagan and Davila, 1997).

Several studies looked at obesity and labour market outcomes and the they generally found poorer labour market outcomes in women, while the results for men were more mixed (Burkhauser and Cawley, 2008, Cawley, 2004, Cawley, 2000, Norton and Han, 2008, Sabia and Rees, 2012, Renna and Thakur, 2010, Averett and Korenman, 1993, Shimokawa, 2008, Han et al., 2009) (Greve, 2008, Johansson et al., 2009, SarlioLähteenkorva and Lahelma, 1999, Bozoyan and Wolbring, 2011, Averett et al., 2012) (Asgeirsdottir, 2011, Rooth, 2009) (Garcia and Quintana-Domeque, 2007, Brunello and d'Hombres, 2007, Atella et al., 2008, Villar and Quintana-Domeque, 2009, Baum and Ford, 2004).

The aim of this paper is to examine the impact of BMI on employment status. The likelihood of employment is particularly interesting, as holding a job is a prerequisite for general labour market performance like wages and on-job performance. Two studies 
have done this using UK data and IV-regression methods. Morris (2007) investigated the impact of obesity on employment (measured as a binary variable) and found a negative effect of obesity on employment in both men and women. Lindeboom et al. (2010) studied the impact of obesity on employment (measured as a binary variable) and found a negative impact of obesity on employment in both men and women. However, the IVregression models, which used biological relatives BMI as instruments, did not support the findings.

One might organise employment status as a multinomial choice variable, where the effect of the obesity variable is allowed to differ for various employment outcomes (e.g. disabled, retired and employed)(Renna and Thakur, 2010, Terza, 2002). Such approaches can provide more complex results, which can answer why and how obesity affects employment status. This paper makes two contributions to the literature. First, it estimates the impact of obesity on employment status as a multinomial dependent variable. Second, covering a period from 1998-2013, the data is more recent than earlier British studies. This is important as obesity rates have increased and the composition of the obese population has changed.

\section{Data and variables}

The analysis is based on data from sixteen rounds (1998-2013) of the Health Survey for England (HSE) ${ }^{1}$ (National Centre for Social Research and Department of Epidemiology and Public Health University College London (UCL), 1997 - 2012); 2013 is the most recent year of data available ${ }^{2}$.

An individual's employment status can be either employed (WORK); looking for paid work (LOOKING); permanently not working due to disability (DISABLED); and, looking

\footnotetext{
1 The HSE is a repeated cross-sectional survey which draws a different sample of nationally representative individuals living in England each year. The sample is selected using a multi-stage stratified probability sampling design with postcode sectors selected at the first stage and household addresses within postcode sectors selected at the second stage. Stratification is based on geographical areas and not on individual characteristics.

2 All adults (16+) within the household (up to a maximum of 10) are eligible for interview, plus up to 2 children (0-15). The interviewer randomly selects the children to interview in a household with more than 2 children. For children aged 0-12, parents answer on behalf of the child but the child is present.
} 
after home or family (HOME/FAMILY). Work included self-employment, part- and fulltime employment ${ }^{3}$.

One useful feature of the HSE is that height and weight are not self-reported, which reduces the likelihood of measurement error. Obesity measured is defined according to World Health Organization guidelines (World Health Organization, 1995). I measure obesity as a binary variable taking the value one if an individual has a BMI $\geq 30 \mathrm{~kg} / \mathrm{m}^{2}$ and zero otherwise. BMI are entered linearly as continuous variables and obesity as a binary variable defined using both BMI.

I include three set of covariates: characteristics of the adult ${ }^{4}$, characteristics of the child and health variables (table 1). The analysis is stratified by gender and is restricted to individuals aged 30 to 49. The reason for this is that these individuals are most likely to: 1) have finished their education, but still be in the labour market; 2) have children in the age range 11-21, which are used for the instrumental variable approach.

\subsection{Instrument}

I follow previous studies and use the BMI of a biological relative as an instrument for BMI and obesity (Cawley, 2004, Cawley and Meyerhoefer, 2012, Lindeboom et al., 2010, Kline and Tobias, 2008, Trogdon et al., 2008). I use the oldest (aged 11-21) biological child's BMI as an instrument for parents BMI. The first requirement of an instrument is that it is highly correlated with variables being instrumented conditional on the other variables in the model. Hence, I run F-tests to check that the instruments exceeds the benchmark value of $F=10$ (Staiger and Stock, 1997). The second requirement of an instrument is that it must not be correlated with the error term in the outcome equation conditional on the other covariates in the model. There are potential pitfalls with the

\footnotetext{
${ }^{3}$ There also is a small amount of individuals with other activity status in the sample: early-retired individuals ( $0.1 \%)$; on a government scheme for employment training $(0.1 \%)$; doing unpaid work for a business that you/relative owns ( $0.1 \%)$; waiting to take up paid work already obtained $(0.3 \%)$; doing unpaid work for a business that you/relative owns $(0.2 \%)$; intending to look for work but prevented by temporary sickness ( $0.5 \%)$; and, doing something else (0.2\%). Due to the small numbers these are excluded from further analysis.

${ }^{4}$ I have included smoking status, marital status and education as these behavioural characteristics may affect both BMI and employment status. However, BMI might also affect these variables. Hence, part of the causal impact of BMI might be controlled for by these covariates. I have fitted models without these variables. Although the estimates vary depending on the covariates, it does not change the main conclusions.
} 
instrument used ${ }^{5}$. However, the validity has been supported in a number of studies. In this short report I will refer to the discussions in related literature for information about the validity of the instrument ${ }^{6}$.

\section{Analysis and estimation}

I model employment status for individual $i$ as:

$Y_{i}=c_{0}+c_{1} B_{i j}+X_{i} \gamma+u_{i}$

where $Y$ is a categorical measure of employment status; $B$ is a measure of BMI or obesity; and $X$ is a vector of individual, household and child's characteristics. $u$ is an error term and $c$ and $\gamma$ are coefficients to be estimated. My primary models are multinomial logit models for each of the outcomes. I test the Independence of Irrelevant Alternatives assumption (IIA) in each regression.

To distinguish if the effect of $B$ on $Y$ is attenuated or explained by health variables $(H)$ I follow earlier literature and estimate an additional specification (Renna and Thakur, 2010, Mosca, 2013):

$Y_{i}=c_{0}+c_{1} B_{i j}+X_{i} \gamma+H_{i} \delta+u_{i}$

Although $H$ can be both endogenous and exogenous a significant effect of B will suggest that BMI has an impact on employment status which is not related to health.

I also use IV regression methods that account for the fact that the outcome measure is a multinomial measure, while the endogenous variables can be either continuous (BMI) or

\footnotetext{
${ }^{5}$ The identifying assumption is that weight of a biological child is strongly correlated with the respondent's weight, but uncorrelated with residual employment outcomes. A large literature supports a strong genetic component to weight, and that any similarity in weight due to shared environment is non existing or very small. Another potential issue is that the genes that are correlated with obesity are also correlated with other behaviour that directly affects residual employment outcomes. Control variables for some types of behaviour (smoking and alcohol consumption) are included, however I am not able to control for everything and like previous literature KLINE, B. \& TOBIAS, J. L. 2008. The wages of BMI: Bayesian analysis of a skewed treatment-response model with nonparametric endogeneity. Journal of Applied Econometrics, 23, 767-793, CAWLEY, J. 2004. The impact of obesity on wages. Journal of Human Resources, 39, 451-474., I acknowledge this as a possible limitation.

${ }^{6}$ For detailed discussions see: Cawley \& Meyerhoefer (2012) page 220; Cawley (2004) page 464-5; and, Lindeboom et la. (2010) page 311-2.
} 
binary (obesity). Two-stage least squares may provide biased estimates in this setting (Terza et al., 2008, Grabowski et al., 2013), hence I apply a control function method (Terza et al., 2008). The first stage is estimated by OLS:

$B_{i}=a_{0}+a_{1} Z_{i}+X_{i} \alpha+u_{1 i}$

where $a, \alpha$ and $\beta$ are coefficients to be estimated, and $Z$ is the instrument that is correlated with $B$ but not $u_{1}$. Based on this model I predict the response residuals $\left(\hat{u}_{1 i}\right)$ which I include as a regressor in the second stage multinomial logit model:

$Y_{i}^{*}=b_{0}+b_{1} B_{i}+X_{i} \beta+b_{2} \hat{u}_{1 i}+u_{2 i}$

The z-scores are based on standard errors, which account for the two-step nature of the estimation, obtained using bootstrapping. I also run IV-models controlling for $H$ as explained in Eq. 2.

Given that the instrument is valid; the IV-model no longer has endogenity problems and an F-test of the residual $\left(b_{2}\right)$ is a direct test of endogeneity. Under the null hypothesis that the dependent variable (BMI or obesity) is exogenous the coefficient on the residuals will be zero. If we fail to reject the null hypothesis then, assuming the instruments are valid, it is not possible to identify any endogeneity problems with respect to the dependent variable and the non-IV estimates are preferred because they have lower standard errors (Baum et al., 2003, Morris, 2006).

I apply survey weights reported in the HSE to each observation. To account for the sampling strategy used in the HSE I control for clustered sampling within Primary Sampling Units (PSUs), using unique PSU/year identifiers that produce Huber/White/sandwich robust variance estimators that allow for within-group dependence (Kish and Frankel, 1974).

I compute elasticity's and marginal effects (M.E.), fixing the covariates at their whole sample mean values. 


\section{Results}

In the IV samples the each individual has a child (aged 11-21), which are used to generate the instrument. Compared with the full sample the IV sample has a higher mean age, lower education, more non-white, fewer singles, more adults and children in household (Table 1). Hence, there are differences across the samples.

The F-tests in the first stages of the IV-models easily exceeds the non-weakness requirement. The coefficients have a positive sign showing that, as expected, children's BMI is positively associated with adult obesity (results available from author upon request).

No violations of the IIA assumption were identified. Focusing on the not health adjusted models first (Table 2). I find that, in men and women, both BMI and obesity are significantly associated with DISABELED. The IV-models supports this finding. Mixed associations between LOOKING and BMI and obesity were found across the non-IV models and the IV-models in both men and women. For HOME/FAMILY positive and significant association between both BMI and obesity were found in women. This was not replicated in the IV-models, though the endogeneity tests were not significant. The Wald tests of equal coefficients (Table 2) support a heterogeneous impact of BMI and obesity on employment status.

In the health adjusted models the only significant association was between BMI and LOOKING in men, however this finding was not significant in the IV models. I interpret these results to suggest that obesity does not affect employment status, unless it affects health.

The results in the non-IV models (Table 2) were based on the full sample. I repeated the analysis in the IV sample (results available from author upon request) and the results are comparable, with some deviations. In general the coefficients values were higher. For example, the elasticity between BMI and DISABELED in men is 1 in the full sample and 2.2 in the IV-sample.

\section{$\underline{\text { 5. Conclusion }}$}


I found BMI and obesity had a significant positive impact on employment disability in both men and women. The results were significantly different when I looked at the impact of obesity on the probability of not working for other reasons. This result supports the prior expectation that BMI and employment status measured by a multinomial choice provide new insight into how obesity affects the labour market. I do not get identical results in the IV-models; however I do not detect significant endogeneity in neither men nor women. I also found that when I control for health variables the impact of obesity on employment status becomes non-significant. This suggests that factors other than health may be less important in explaining the impact of BMI or obesity on employment.

This study has limitations. First, I include BMI as a linear variable, when there is evidence of non-linear associations between BMI and health. Similarly, I compare obese to the non-obese whereas other papers include multiple BMI categories (Kinge and Morris, 2010) (I do not include indicators for these categories as I lack additional instruments). Second, because of the instrument used in the IV models, I was forced to limit the sample to adults with a biological child between the ages of 11-20. As a result the IV-results may not generalize to the entire population. Third, there may be issues with the validity of the instrument and it is important to recognise this as a limitation when interpreting the findings.

To conclude, the findings in this study demonstrate that obesity has a negative impact on employment through permanent employment disability in both men and women. This is likely to arise because obesity is a debilitating health condition that has an independent effect on the ability to work. 
Table 1: Summary statistics of the samples by covariates

\begin{tabular}{|c|c|c|c|c|c|}
\hline Variable Name & $\begin{array}{l}\text { BMI-Full } \\
\text { sample }\end{array}$ & $\begin{array}{l}\text { BMI-IV } \\
\text { sample }\end{array}$ & Variable Name & $\begin{array}{l}\text { BMI-Full } \\
\text { sample }\end{array}$ & $\begin{array}{l}\text { BMI-IV } \\
\text { sample }\end{array}$ \\
\hline Total (N) & 48297 & 14155 & BMI (mean) & 27.1 & 27.4 \\
\hline Male (N) & 21678 & 4818 & Obese $(\%)$ & $23.3 \%$ & $24.9 \%$ \\
\hline Female $(\mathrm{N})$ & 26619 & 9337 & & & \\
\hline \multicolumn{6}{|c|}{ Covariates used in the regressions } \\
\hline Age (mean) & 39.6 & 41.9 & Cigarettes (\%) & & \\
\hline Education qualifications (\%) & & & Never smoked & 47.2 & 47.2 \\
\hline Degree & 24.9 & 17.1 & Used to smoke & 25.4 & 25.7 \\
\hline Higher education below degree & 13.0 & 12.8 & Current smoker & 27.4 & 27.1 \\
\hline GCE A level equivalent & 14.7 & 14.0 & GOR of residence $(\%)$ & & \\
\hline GCE $O$ level equivalent & 27.3 & 31.2 & North East & 6.2 & 6.8 \\
\hline CSE other grade equivalent & 5.1 & 6.1 & North West & 14.1 & 15.0 \\
\hline Foreign/other & 1.4 & 1.7 & Yorkshire and The Humber & 10.2 & 11.4 \\
\hline No qualification & 13.6 & 17.2 & East Midlands & 9.8 & 10.6 \\
\hline Ethnicity & & & West Midlands & 10.0 & 10.6 \\
\hline Non-white & 10.8 & 11.4 & East of England & 11.3 & 10.8 \\
\hline White & 89.2 & 88.6 & London & 12.6 & 10.7 \\
\hline Marital status (\%) & & & South West & 9.8 & 9.4 \\
\hline Single/divorced & 25.1 & 17.9 & South East & 16.0 & 14.7 \\
\hline Married & 62.0 & 75.5 & Survey year (\%) & & \\
\hline Cohabiters & 12.9 & 6.6 & 1998 & 10.8 & 11.5 \\
\hline Number of children $(\%)^{1}$ & & & 1999 & 5.3 & 5.7 \\
\hline 0 & 44.1 & 18.7 & 2000 & 5.2 & 5.5 \\
\hline 1 & 23.4 & 30.9 & 2001 & 9.7 & 10.3 \\
\hline 2 & 23.9 & 35.6 & 2002 & 4.2 & 5.8 \\
\hline 3 or more & 8.7 & 14.8 & 2003 & 4.7 & 10.5 \\
\hline Adults in household & & & 2004 & 8.9 & 4.3 \\
\hline 1 & 16.2 & 8.5 & 2005 & 4.3 & 4.8 \\
\hline 2 & 61.8 & 47.0 & 2006 & 8.9 & 8.9 \\
\hline 3 & 15.0 & 30.2 & 2007 & 2.9 & 4.2 \\
\hline 4 & 5.8 & 12.0 & 2008 & 4.9 & 8.7 \\
\hline 5 & 1.0 & 1.9 & 2009 & 5.0 & 2.7 \\
\hline 6 & 0.2 & 0.3 & 2010 & 4.6 & 4.6 \\
\hline 7 & 0.1 & 0.1 & 2011 & 5.2 & 4.1 \\
\hline 8 & 0.0 & 0.0 & 2012 & 4.6 & 4.0 \\
\hline 9 & 0.0 & 0.0 & 2013 & 5.2 & 4.5 \\
\hline Age of the child* & NA. & 15.2 & Child tried cigarettes (yes $=1$ )* & NA. & 23.1 \\
\hline Gender of the child (girl=1)* & NA. & 49.1 & Child tried alcohol* & NA. & 42.9 \\
\hline \multicolumn{6}{|c|}{ Covariates used in the health adjusted regressions only } \\
\hline Self-assed health & & & Limiting longlasting illnesses & & \\
\hline Very good & 39.6 & 37.3 & Limiting longlasting illness & 17.1 & 18.0 \\
\hline Good & 43.3 & 44.5 & Non limiting longlasting illness & 16.9 & 17.2 \\
\hline Fair & 13.3 & 14.1 & No limiting longlasting illness & 66.0 & 64.8 \\
\hline Bad & 3.02 & 3.2 & & & \\
\hline Very bad & 0.8 & 0.9 & & & \\
\hline
\end{tabular}

Number of children between the age of 2-15

*These variables are included in each regression. In the non-IV sample, which consists of individuals without children, I include a missing category for these variables. 
Table 2: elasticity (BMI) and marginal effect (obesity) and employment status (reference group=WORK), endogeneity tests and Wald tests for equal coefficients across the models.

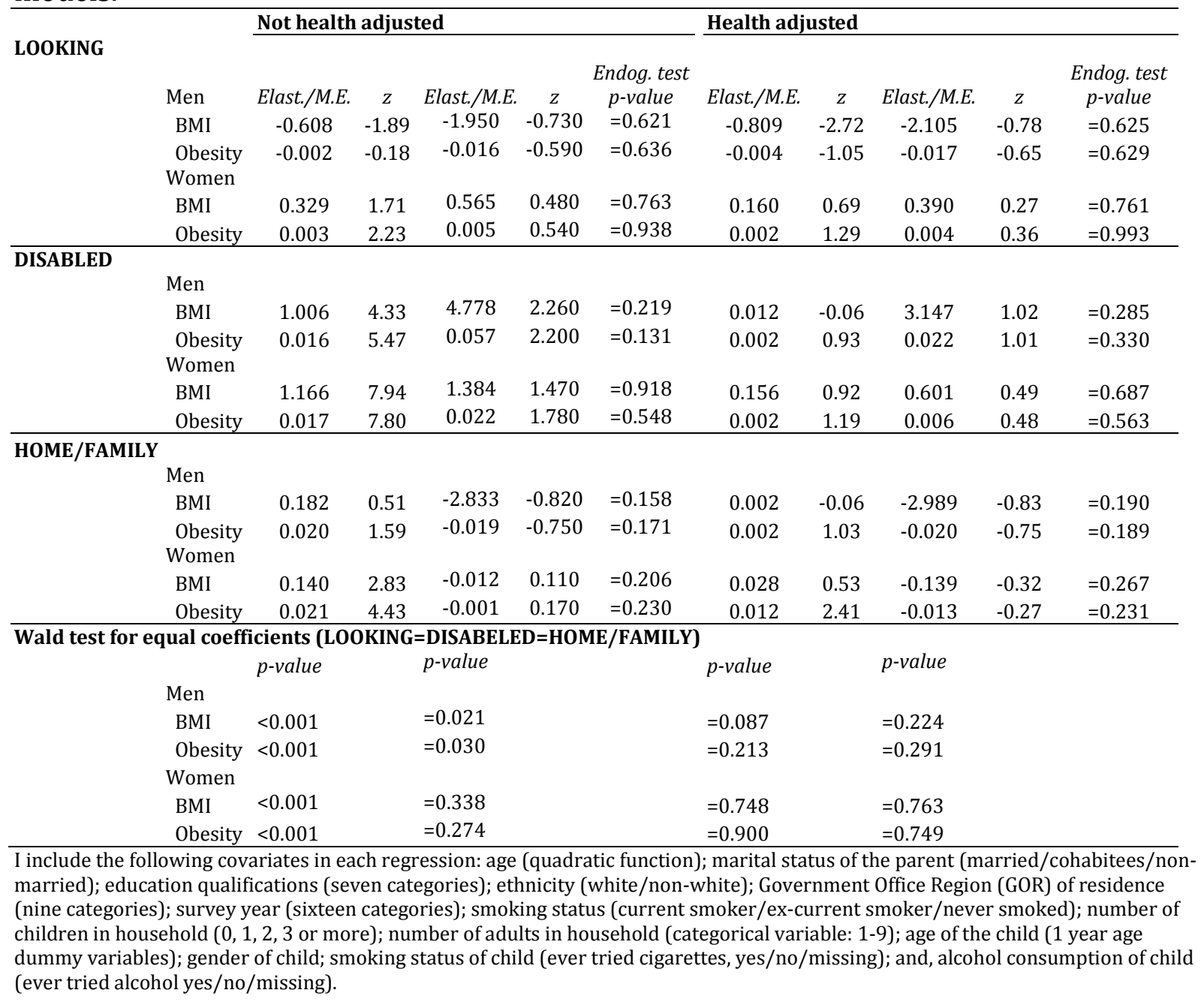

\section{$\underline{\text { References }}$}

ASGEIRSDOTTIR, T. L. 2011. Do body weight and gender shape the work force? The case of Iceland. Economics \& Human Biology, 9, 148-156.

ATELLA, V., PACE, N. \& VURI, D. 2008. Are employers discriminating with respect to weight?: European Evidence using Quantile Regression. Economics \& Human Biology, 6, 305-329.

AVERETT, S. \& KORENMAN, S. 1993. The economic reality of the beauty myth. National Bureau of Economic Research.

AVERETT, S. L., ARGYS, L. M. \& KOHN, J. L. 2012. Immigration, obesity and labor market outcomes in the UK. IZA Journal of Migration, 1, 1-19.

BAUM, C. F., SCHAFFER, M. E. \& STILLMAN, S. 2003. Instrumental variables and GMM: Estimation and testing. Stata journal, 3, 1-31.

BAUM, C. L. \& FORD, W. F. 2004. The wage effects of obesity: a longitudinal study. Health Economics, $13,885-899$.

BOZOYAN, C. \& WOLBRING, T. 2011. Fat, muscles, and wages. Economics \& Human Biology, 9, 356363.

BRUNELLO, G. \& D'HOMBRES, B. 2007. Does body weight affect wages?: Evidence from Europe. Economics \& Human Biology, 5, 1-19. 
BURKHAUSER, R. V. \& CAWLEY, J. 2008. Beyond BMI: the value of more accurate measures of fatness and obesity in social science research. Journal of health economics, 27, 519-529.

CAWLEY, J. 2000. Body weight and women's labor market outcomes. National bureau of economic research.

CAWLEY, J. 2004. The impact of obesity on wages. Journal of Human Resources, 39, 451-474.

CAWLEY, J. \& MEYERHOEFER, C. 2012. The medical care costs of obesity: an instrumental variables approach. Journal of health economics, 31, 219-230.

EVERETT, M. 1990. Let an overweight person call on your best customers? Fat chance. Sales and Marketing Management, 142, 66-70.

GARCIA, J. \& QUINTANA-DOMEQUE, C. 2007. Obesity, employment, and wages in Europe. Advances in health economics and health services research, 17, 187-217.

GRABOWSKI, D. C., FENG, Z., HIRTH, R., RAHMAN, M. \& MOR, V. 2013. Effect of nursing home ownership on the quality of post-acute care: An instrumental variables approach. Journal of health economics, 32, 12-21.

GREVE, J. 2008. Obesity and labor market outcomes in Denmark. Economics \& Human Biology, 6, 350-362.

HAN, E., N, E. C. \& STEARNS, S. C. 2009. Weight and wages: fat versus lean paychecks. Health economics, 18, 535-548.

JOHANSSON, E., BÖCKERMAN, P., KIISKINEN, U. \& HELIÖVAARA, M. 2009. Obesity and labour market success in Finland: The difference between having a high BMI and being fat. Economics \& Human Biology, 7, 36-45.

KINGE, J. M. \& MORRIS, S. 2010. Socioeconomic variation in the impact of obesity on health-related quality of life. Social science \& medicine, 71, 1864-1871.

KISH, L. \& FRANKEL, M. R. 1974. Inference from complex samples. Journal of the Royal Statistical Society. Series $B$ (Methodological), 1-37.

KLINE, B. \& TOBIAS, J. L. 2008. The wages of BMI: Bayesian analysis of a skewed treatment-response model with nonparametric endogeneity. Journal of Applied Econometrics, 23, 767-793.

KOMLOS, J., SMITH, P. K. \& BOGIN, B. 2004. Obesity and the rate of time preference: is there a connection? Journal of biosocial science, 36, 209-219.

LINDEBOOM, M., LUNDBORG, P. \& VAN DER KLAAUW, B. 2010. Assessing the impact of obesity on labor market outcomes. Economics \& Human Biology, 8, 309-319.

MCLEAN, R. A. \& MOON, M. 1980. Health, obesity, and earnings. American Journal of Public Health, 70, 1006-1009.

MORRIS, S. 2006. Body mass index and occupational attainment. Journal of health economics, 25, 347-364.

MORRIS, S. 2007. The impact of obesity on employment. Labour Economics, 14, 413-433.

MOSCA, I. 2013. Body mass index, waist circumference and employment: Evidence from older Irish adults. Economics \& Human Biology, 11, 522-533.

NATIONAL CENTRE FOR SOCIAL RESEARCH AND DEPARTMENT OF EPIDEMIOLOGY AND PUBLIC HEALTH UNIVERSITY COLLEGE LONDON (UCL) 1997 - 2012. Health Survey for England. Colchester, Essex: UK Data Archive

NHLBI OBESITY EDUCATION INITIATIVE 1998. Clinical guidelines on the identification, evaluation, and treatment of overweight and obesity in adults, National Heart, Lung, and Blood Institute.

NORTON, E. C. \& HAN, E. 2008. Genetic information, obesity, and labor market outcomes. Health Economics, 17, 1089-1104.

OFFER, A. 2001. Body weight and self-control in the United States and Britain since the 1950s. Social History of Medicine, 14, 79-106.

PAGAN, J. A. \& DAVILA, A. 1997. Obesity, occupational attainment, and earnings. Social Science Quarterly, 756-770.

RENNA, F. \& THAKUR, N. 2010. Direct and indirect effects of obesity on US labor market outcomes of older working age adults. Social science \& medicine, 71, 405-413. 
ROOTH, D.-O. 2009. Obesity, attractiveness, and differential treatment in hiring a field experiment. Journal of Human Resources, 44, 710-735.

SABIA, J. J. \& REES, D. I. 2012. Body weight and wages: Evidence from Add Health. Economics \& Human Biology, 10, 14-19.

SARLIO-LÄHTEENKORVA, S. \& LAHELMA, E. 1999. The association of body mass index with social and economic disadvantage in women and men. International journal of epidemiology, 28, 445449.

SHIMOKAWA, S. 2008. The labour market impact of body weight in China: a semiparametric analysis. Applied Economics, 40, 949-968.

STAIGER, D. \& STOCK, J. H. 1997. Instrumental Variables Regression with Weak Instruments. Econometrica: Journal of the Econometric Society, 557-586.

TERZA, J. V. 2002. Alcohol abuse and employment: a second look. Journal of Applied Econometrics, 17, 393-404.

TERZA, J. V., BASU, A. \& RATHOUZ, P. J. 2008. Two-stage residual inclusion estimation: addressing endogeneity in health econometric modeling. Journal of health economics, 27, 531-543.

TROGDON, J. G., NONNEMAKER, J. \& PAIS, J. 2008. Peer effects in adolescent overweight. Journal of health economics, 27, 1388-1399.

VILLAR, J. G. \& QUINTANA-DOMEQUE, C. 2009. Income and body mass index in Europe. Economics \& Human Biology, 7, 73-83.

WORLD HEALTH ORGANIZATION 1995. Physical status: The use of and interpretation of anthropometry, Report of a WHO Expert Committee. 